\title{
Design of PLC Based Control System for Rotary Flexible Fixture with PID Compensator
}

\author{
Adi Susanto ${ }^{1}$, Sampurno ${ }^{1}$, and Suhardjono ${ }^{1}$
}

\begin{abstract}
Machining process consist of machine tool, cutting tool and work piece that must securely held by jig and fixture. A rotary flexible fixture prototype then developed, to locate work piece at desired angular position using rotary and tilt angular positioning components to complement machining processes such as CNC mill, EDM, machining center, etc. This research focused on designing PLC based control system with PID compensator for the prototype, this paper however deal with rotary component in particular. Preliminarily, all components assembled into closed-loop transfer function and calculated its frequency domain overall transfer function. Analysis of control system stability then followed, using such methods as RouthHurwitz, Nyquist and Root Locus. Next, the system's time responses need to be evaluated, design targets are rise time less than 0.2 second, settling time not exceeding 0.4 second and zero steady state error with $\pm 2 \%$ allowable error. If target are not satisfied, then use of PID compensator. Stability analysis results shows the system are stable according to Routh-Hurwitz, Root Locus, and Nyquist criteria. Time responses analysis results in rise time 0.267 second and settling time 0,476 second. While, the system yield zero steady state error. To meet design targets, PID compensator were employed, after tuning at proportional gain value 1.5, rotary component reached rise time 0,178 second, settling time 0,317 second, well within design target. These results are essential for PLC programming, assembly process and general consideration or recommendation for selecting components to gain a simple yet better perform control system.
\end{abstract}

Keywords—Rotary Angular Positioning, Stability, Frequency Response, Time Respons

\section{INTRODUCTION}

$\mathrm{T}_{\mathrm{i}}^{\mathrm{k}} \mathrm{d}$ The demand for manufactured goods is growing, industry has responded to this demand with many ways of making this product, resulting in more advance and dramatic change in manufacturing process. These change call for more cost-effective and efficient work holding method and device. The basic requirement of holding the workpiece has remained constant, the workpiece need to accurately located and securely held throughout the machining processes [1]. The prototype of Rotary flexible fixture added two axes for such machining processes as CNC milling and sinking EDM. As locating and clamping element, this prototype use 3 jaw or 4 jaw chuck, according to workpiece geometry alternatively. Workpieces positioned and held secure at desired angle, this research paper focus on $0^{\circ}-360^{\circ}$ angle position adjuster, further we use term rotary angular positioning component for this feature. To ensure fast and accurate angle positioning, the use of control system are essential, it decrease setup-time, minimize human's error, and increase working safety. PLC based control system are selected for its ruggedness, robustness and user friendly graphical ladder programming language [2]-[4]. Lower setup-time ensure the efficiency of machining process, eventually lead to lower machining cost. The use of this prototype on a workshop or machining industry could help to suppress end products price, and maintain profitable operations.

\footnotetext{
${ }^{1}$ Adi Susanto, Sampurno, and Suhardjono are with Departement of Mechanical Engineering, Institut Teknologi Sepuluh Nopember, Surabaya, 60111, Indonesia. E-mail: adisst@gmail.com; tsanisam@me.its.ac.id; suhardjono@me.its.ac.id.
}

The objectives of this research are designing a PLC based control system for rotary flexible fixture prototype. As this control system to be use to move a mechanical load, it need to be examined for its stability according to loads it moves. And last but not least utilize PID compensator to reach design target of rise time 0.2 seconds and settling time 0.4 seconds.

Design result could be used to enhance rotary flexible fixture's function, easy and save to operate, while still maintain good quality of end product, it could also to be used for general consideration or recommendation for selecting control components for better performance, so this prototype are good enough for any workshops or machining industry needs. Finally, this research offers reference for machining industry and community.

\section{METHOD}

All information about sensors, correcting elements, control system stability, time response, PID compensator, and PLC programming were gathered. Another essential information being dimension and construction of the rotary flexible fixture that gathered by the mean of field study. Figure 1 shows design process flowchart.

From selected components specification such as sensor, correcting element, and mechanical loads, we can find its state space equations, by assemble these equations into close loop system with help of software MATLAB 2015a, then we can find its overall transfer function and characteristic equation. Stability of the control system can be examined by the recently found characteristic equation, using Routh-Hurwitz, Root Locus and Nyquist methods.

Control system's stability were essential property but does not represent system's performance. Another 
examination were then employed, by giving step input to the system and examine its time response, respectively, rise time, settling time and steady state error, all these value must fall within design target of 0.2 seconds for rise time,
0.4 seconds for settling time and zero steady state error with allowable error $\pm 2 \%$. Figure 2 shows stability analysis and PID compensation.

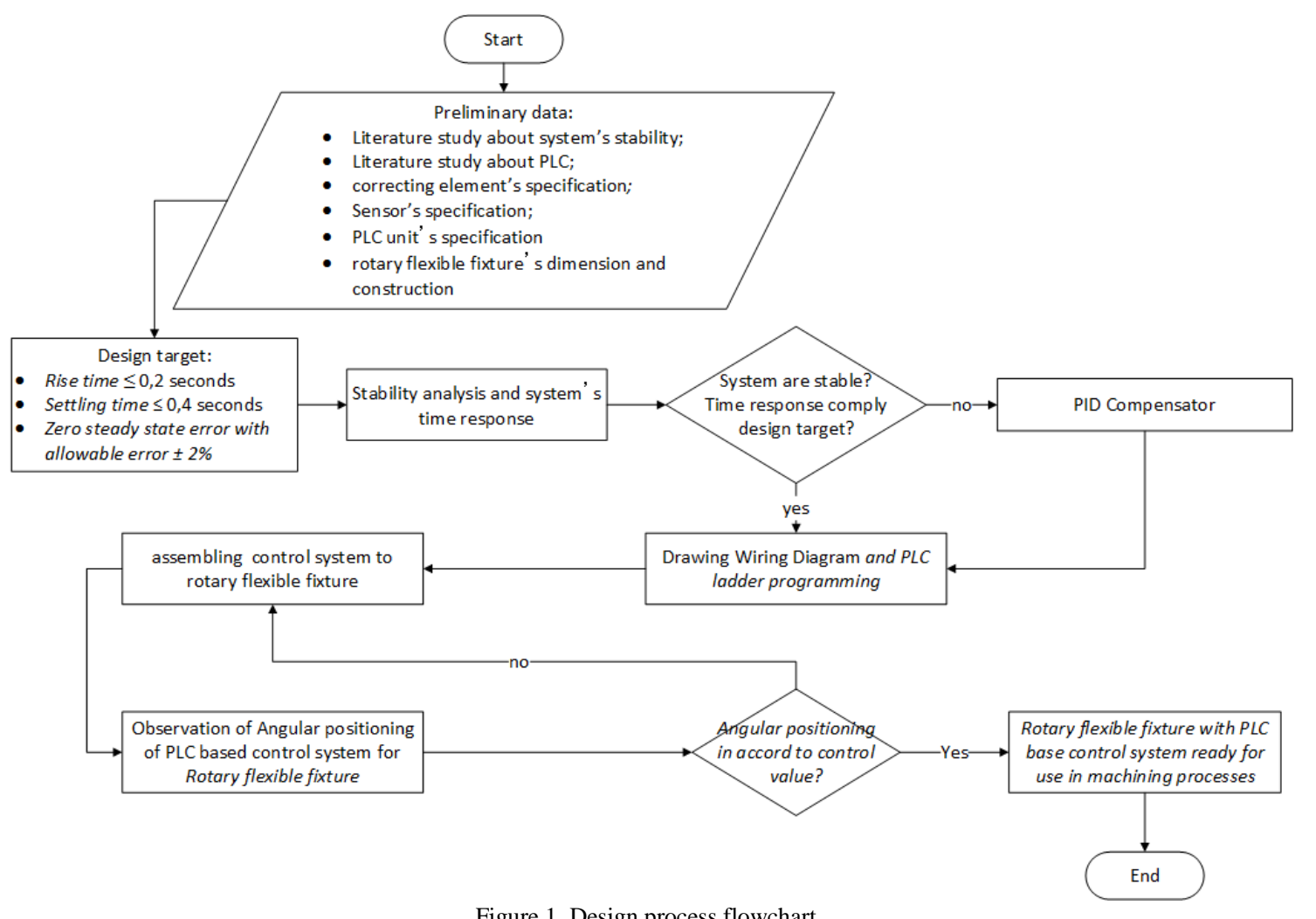

Figure 1. Design process flowchart.

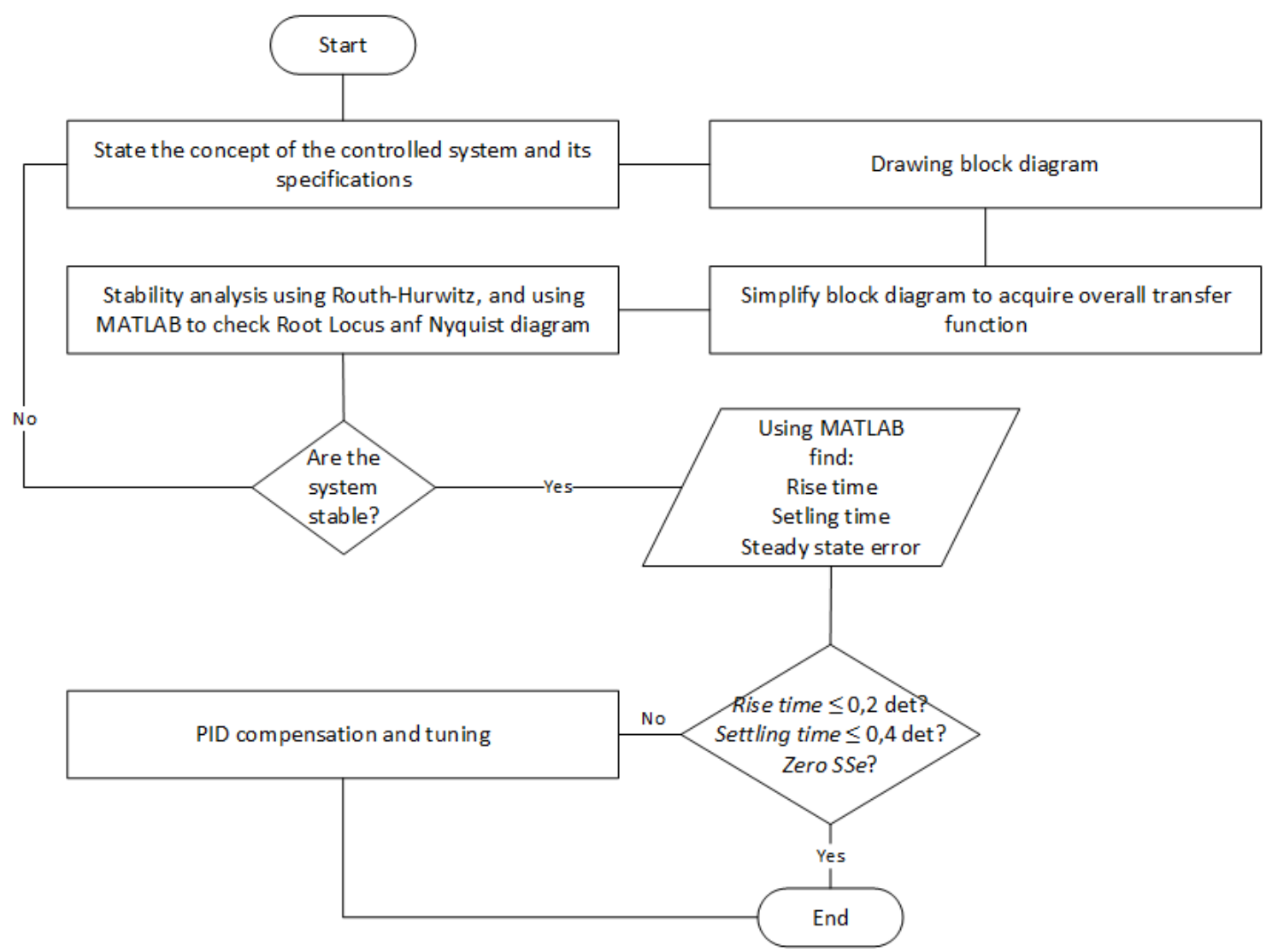

Figure 2. Stability analysis and PID compensation. 


\section{RESUlt AND DISCUSSION}

Rotary flexible fixture are a work holding device that hold and direct the workpiece to desired angular position, so the workpiece can be machined at that angle. This device will added two axis to designated machine, rotary angular positioning component work on rotary axis $\mathrm{C}$ that goes around $W^{\prime}$ axis, as shown in Figure 3.

The control system for rotary angular positioning component is an electro-mechanical system it draw electrical energy, converted into mechanical torque by dc motor to drive mechanical load, set point angular position given by an angular sensor, similar sensor placed at the end of rotary angular positioning component's spindle acting as negative feedback, these two sensors connected to PLC as controller, output from PLC use to drive DC motor as correcting element via motor driver, to change the direction of motor DC rotation and reduce its high angular velocity to desired speed a pair worm and worm-gear were selected as transmission. All of control system's components assembled into a layout, as can be seen at Figure 4.

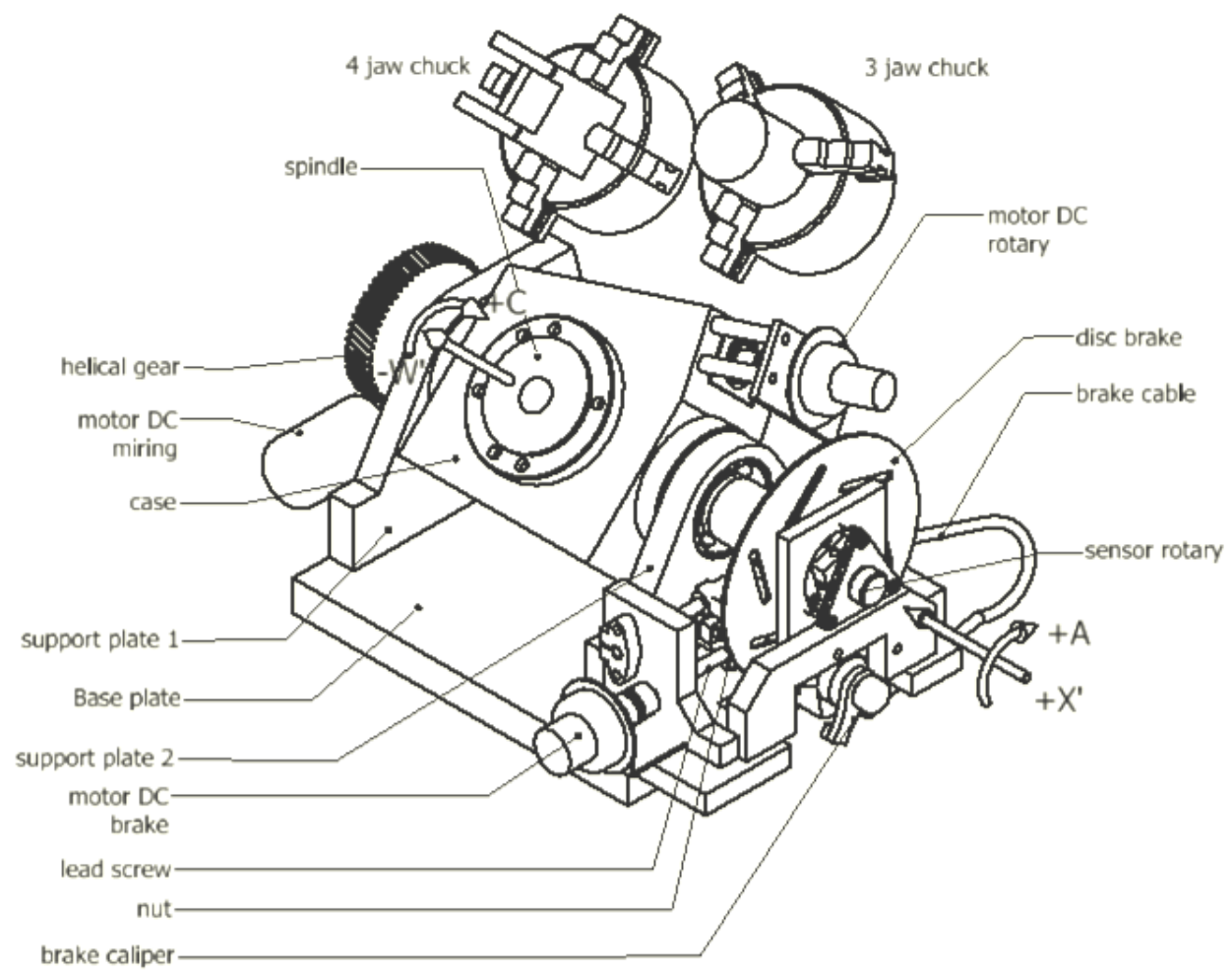

Figure 3. Illustration of Rotary flexible fixture’s constructions

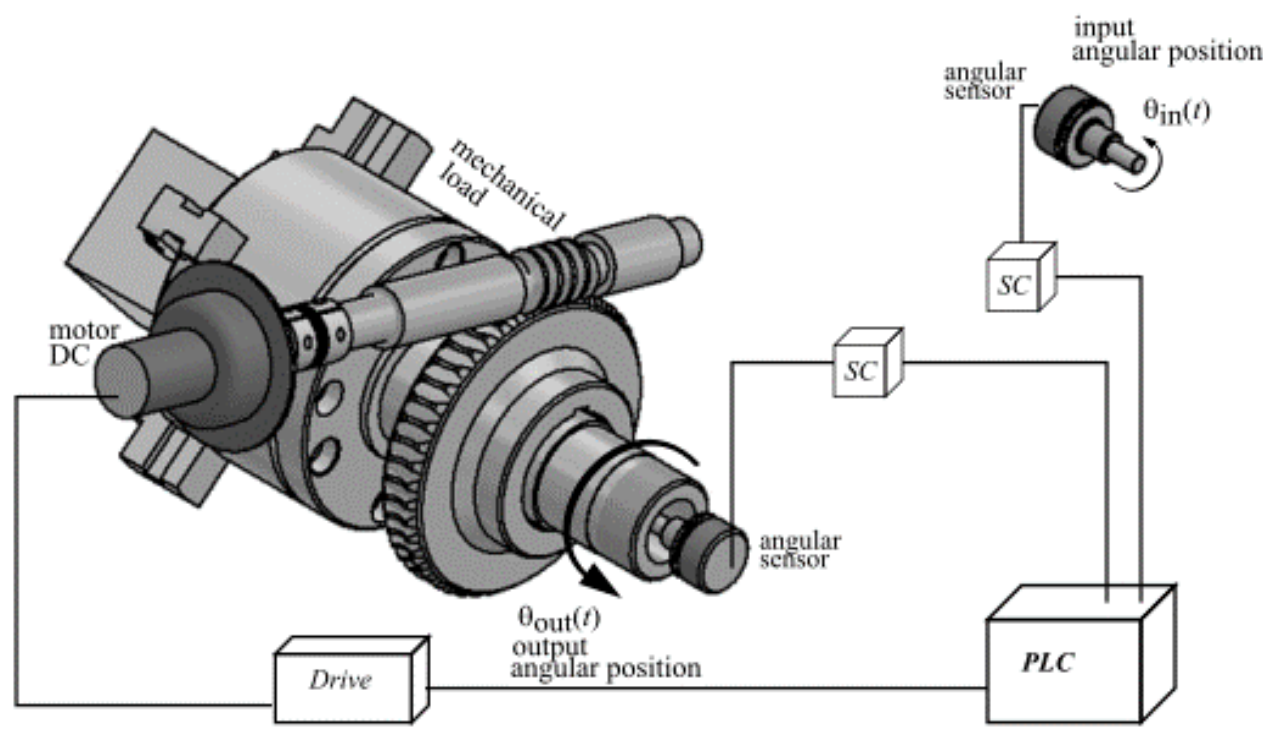

Figure 4. Rotary angular positioning component's control system layout. 
TABLE 1.

CONTROL SYSTEM'S COMPONENTS VALUE

\begin{tabular}{|c|c|c|c|c|c|}
\hline Component's description & symbol & value & Component's description & symbol & value \\
\hline Set point and sensor constant & $K_{S C}$ & $5 / \pi$ & DC motor armature's resistance & $\mathrm{R}_{\mathrm{a}}$ & $3.1[\mathrm{Ohm}]$ \\
\hline Controller gain & $\mathrm{K}_{\mathrm{p}}$ & 1 & DC motor armature's inductance & $\mathrm{L}_{\mathrm{a}}$ & $1.746082 \times 10^{-3}[$ Henries $]$ \\
\hline DC motor's driver gain & $\mathrm{K}_{\mathrm{dr}}$ & 4.8 & $\begin{array}{l}\text { Equivalent mechanical load's mass } \\
\text { moment of inertia }\end{array}$ & $\mathrm{J}_{\mathrm{e}}$ & $2.278 \times 10^{-6}\left[\mathrm{~kg} \cdot \mathrm{m}^{2}\right]$ \\
\hline DC motor's torque constant & Kt & $0,093[\mathrm{Nm} / \mathrm{A}]$ & Equivalent mechanical load's damping & $\mathrm{D}_{\mathrm{e}}$ & $3.244 \times 10^{-5}[\mathrm{Nms} / \mathrm{rad}]$ \\
\hline DC motor's speed constant & $\mathrm{K}_{\mathrm{b}}$ & 0,093 [Vs/rad] & Worm gear ratio & $\mathrm{N}$ & $1 / 58$ \\
\hline
\end{tabular}

TABLE 2.

\begin{tabular}{crrr}
\multicolumn{4}{c}{ ROUTH TABLE OF CHARACTERISTIC EQUATION } \\
\hline \hline $\mathrm{s}^{3}$ & 1 & $2,175 \times 10^{8}$ & 0 \\
$\mathrm{~s}^{2}$ & 1790 & $1,786 \times 10^{9}$ & 0 \\
$\mathrm{~s}^{1}$ & $2,165 \times 10^{8}$ & 0 & 0 \\
$\mathrm{~s}^{0}$ & $1,786 \times 10^{9}$ & 0 & 0 \\
\hline
\end{tabular}

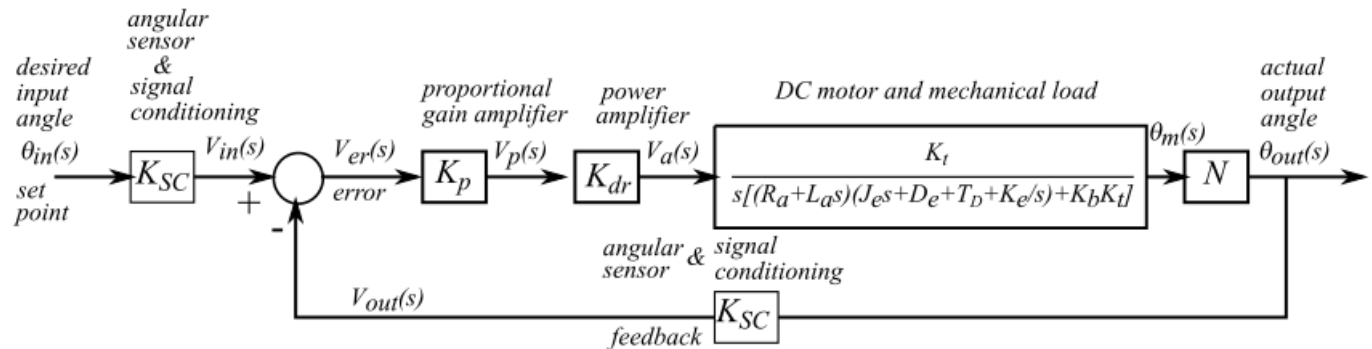

Figure 5. Rotary angular positioning component’s block diagram.
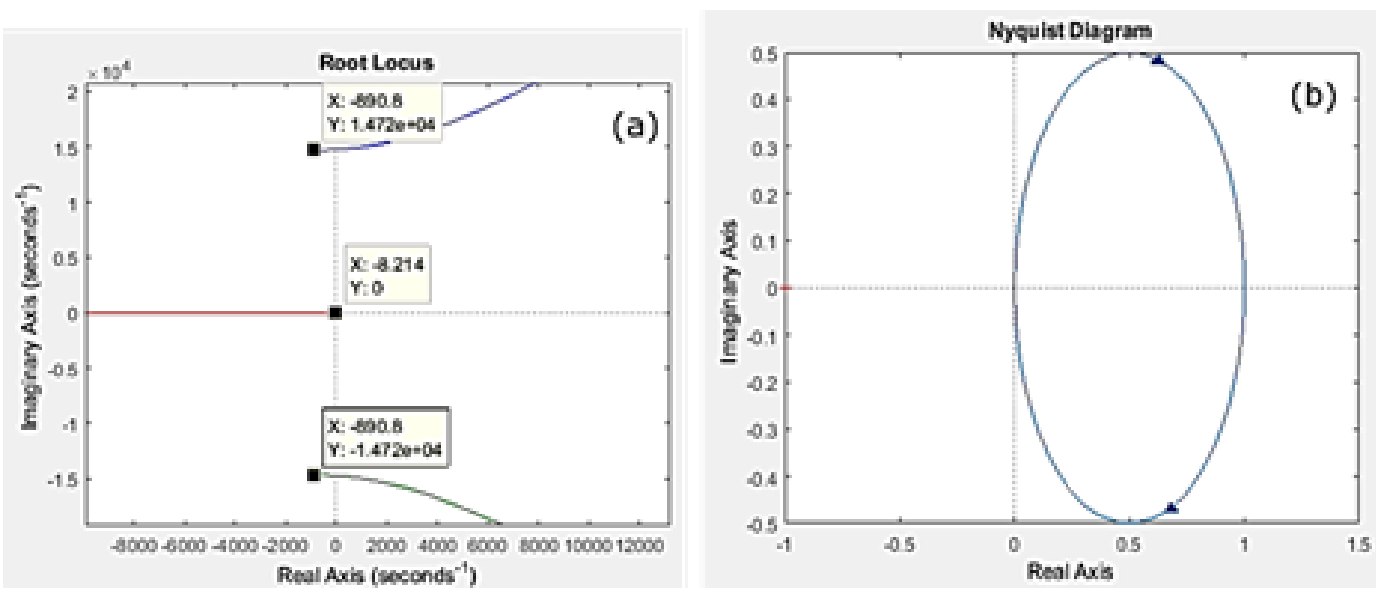

Figure 6. (a) Root locus of control system; (b) Nyquist diagram of control system

TABLE 3.

SYSTEM'S RESPONSE CHARACTERISTICS

\begin{tabular}{ll}
\hline \hline System's response characteristics & \multicolumn{1}{c}{ Value } \\
\hline RiseTime & 0,2675 second \\
SettlingTime & 0,4763 second \\
SettlingMin & 0,9045 \\
SettlingMax & 1.0000 \\
Overshoot & $0 \%$ \\
Undershoot & $0 \%$ \\
Peak & 1 \\
PeakTime & 1,2839 second \\
\hline \hline
\end{tabular}


The layout converted into block diagram shown in figure 5, each blocks represent each components in frequency domain form, and this diagram need to manipulate further to find overall transfer function of the control system. Block diagram manipulation resulting in control system's close loop overall transfer function $\mathrm{T}_{\mathrm{e}}(\mathrm{s})$ :

$$
\begin{aligned}
\mathrm{T}_{\mathrm{e}}(\mathrm{s})= & \theta_{\text {out }}(\mathrm{s}) / \theta_{\text {in }}(\mathrm{s}) \\
= & \left(\mathrm{K}_{\mathrm{SC}} \times \mathrm{K}_{\mathrm{p}} \times \mathrm{K}_{\mathrm{dr}} \times \mathrm{K}_{\mathrm{t}} \times \mathrm{N}\right) / \\
& \left(\mathrm{s}\left[\left(\mathrm{R}_{\mathrm{a}}+\mathrm{L}_{\mathrm{a}} \mathrm{s}\right) \times\left(\mathrm{J}_{\mathrm{e}} \mathrm{s}+\mathrm{D}_{\mathrm{e}}\right)+\mathrm{K}_{\mathrm{b}} \mathrm{K}_{\mathrm{t}}\right]+\mathrm{K}_{\mathrm{sc}} \times \mathrm{K}_{\mathrm{p}} \times \mathrm{K}_{\mathrm{dr}} \times \mathrm{K}_{\mathrm{t}} \times \mathrm{N}\right)
\end{aligned}
$$

Control system's component value, were found by observation and measurement, summarized into Table 1. Substitute each control system's component value into equation 1, using MATLAB, we find equation (2):

$$
\begin{aligned}
\mathrm{T}_{\mathrm{e}}(\mathrm{s}) & =\left(1,789 \times 10^{9}\right) / \\
& \left(s^{3}+1790 s^{2}+2,175 \times 10^{8} s+1,789 \times 10^{9}\right)
\end{aligned}
$$

The denominator of $\mathrm{T}_{\mathrm{e}}(\mathrm{s})$ are the characteristic equation[4] that determine the behaviour of control system, using this equation we could examine stability of the system. The first step of stability analysis were using Routh-Hurwitz method, by arranging the characteristic equation into Routh table, as shown in Table 2, grey out cells were the initial table, while the other cells were the completion of the Routh table.

According to table 2, there were no sign change at first column of Routh table, we can be sure that the system were stable by Routh-Hurwitz criterion [4]. For verification, the system examined further using Root Locus method, by solving the characteristic equation we could find its exact root, in this case the root exist at real axis -8.214 and two poles at imaginary location $-890.8 \pm 1,7 \times 104 j \omega$, all of them were negative value located at left half plane (LHP) indicting this system would reach certain value when time reach infinity [4], another word we could say for certain this system are stable according to Root Locus criteria. Figure 6a shows the root location.

Another way to examine system's stability were via frequency response of its open loop equation written as $G(s) H(s)$, the method were called Nyquist method. By turning the open loop equation into its frequency counterpart $G(j \omega) H(j \omega)$ and plotting the result when the value of $\omega$ were zero to infinity we would end up with a graphical representation known as Nyquist diagram [5], [6]. The examination of system's stability according to Nyquist were quite simple, as long as the diagram does not encircle point $(-1+\mathrm{j} 0)$ then the system was stable. Figure $6 \mathrm{~b}$ represent Nyquist diagram of the rotary component's control system, it shows that the diagram does not encircle point $(-1+j 0)$. We can say, the system were stable according to Nyquist methods.

Stability of the control system does not necessary represent its performance, as stability only tell us that control system would stay at certain value when time reach infinity, but it does not tell what value the system reach and when. One best way to obtain system's performance was via its time response, to acquire time response of the control system [5], with the help of MATLAB, by giving step input $1 / \mathrm{s}$ to closes loop transfer function of the control system, for it is angular displacement we interested in, so we could acquire a graphical results, showing a waveform's amplitude against time, as can be seen at Figure 7. This figure given us information about system performance mainly rise time 0.267 seconds and settling time 0.476 seconds, presented at figure 7 , while other information about system's response were assembled at table 3 .

Another important properties of a control system were its steady state error, as time goes to infinity the stable system's response waveform would saturated into a constant value [5], this property were correspond to angular positioning accuracy and precision of rotary component. For closed loop transfer function, steady state error governed by equation 3 [5].

$$
e_{s s}=\lim _{s=0} s[1-T(s)] \frac{1}{s}
$$

Further calculation yield result equal to 1 , it is mean that the angular output (nominator) and angular input (denominator) were yield equal value, this represent no difference between input and output or it can be said the control system reach zero steady state error.

Previous discussion give us information of rise time rise time 0.267 seconds and settling time 0.476 seconds, outside of design target of rise time 0.2 seconds and settling time 0.4 seconds or less. Using PID compensator, we would improve control system's performance. PID consist of three term, with its own influence to system behaviour, increase proportional gain $K_{p}$ would decrease rise time, increase integral gain $K_{i}$ would increase steady state value and derivative gain $K_{d}$ would eliminate overshoot [7], [8]. For rotary angular positioning control system we only need to use $K_{p}$, other components $K_{i}$ and $K_{d}$ were not needed as the time response does not exhibit overshoot and still reach zero steady state error. Using manual tuning, we found that the system reach rise time 0.178 seconds and settling time 0.317 second, as can be seen in figure 9, well within design target, at $K_{p} 1.5$, table 4 list several value of $K_{p}$ and its corresponding time response. The close loop transfer function would have written as Equation 3.

$$
\begin{aligned}
& T_{e}(s)=\left(2.679 \times 10^{9}\right) / \\
& \left(s^{3}+1790 s^{2}+2.175 \times 10^{8} s+2.679 \times 10^{9}\right)
\end{aligned}
$$

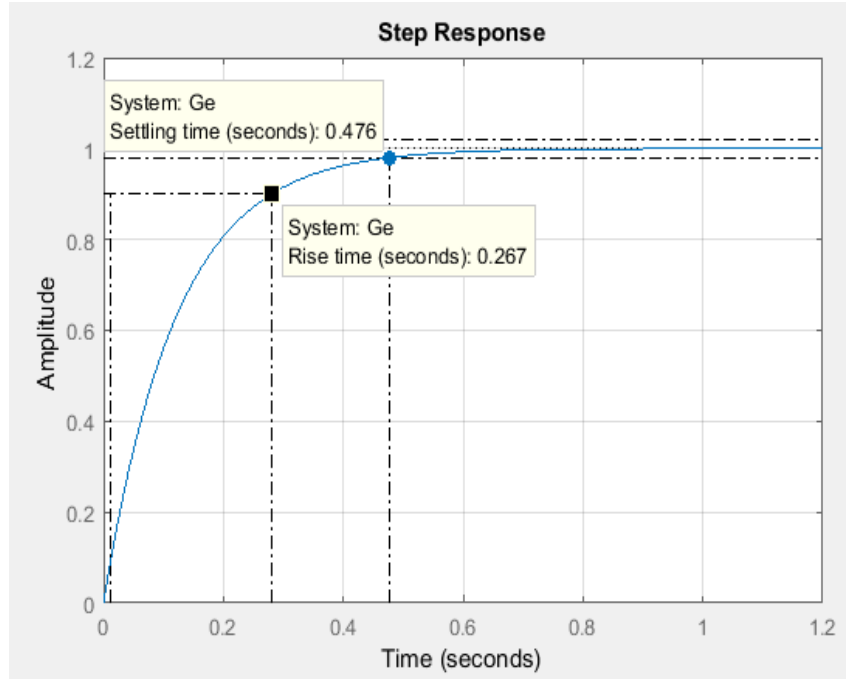

Figure 7. Close loop system’s Time response. 
TABLE 4.

SYSTEM'S RESPONSE CHARACTERISTICS WITH INCREASE OF $\mathrm{K}_{\mathrm{p}}$

\begin{tabular}{ccccc}
\hline \hline $\mathbf{K}_{\mathbf{p}}$ & \multicolumn{2}{c}{ Rotary angular positioning component system } \\
\cline { 2 - 5 } & $\begin{array}{c}\text { Rise } \\
\text { time }\end{array}$ & $\begin{array}{c}\text { Settling } \\
\text { time }\end{array}$ & $\begin{array}{c}\text { Steady state } \\
\text { error }\end{array}$ & $\begin{array}{c}\text { \%Over- } \\
\text { shoot }\end{array}$ \\
\hline 1 & 0,2675 & 0,4763 & 0 & 0 \\
1,5 & 0,1783 & 0,3175 & 0 & 0 \\
2 & 0,1337 & 0,2381 & 0 & 0 \\
2,5 & 0,1070 & 0,1905 & 0 & 0 \\
3 & 0,0891 & 0,1587 & 0 & 0 \\
3.5 & 0,0764 & 0,1361 & 0 & 0 \\
4 & 0,0669 & 0,1191 & 0 & 0 \\
4.5 & 0,0594 & 0,1058 & 0 & 0 \\
5 & 0,0535 & 0,0952 & 0 & 0 \\
15 & 0,0179 & 0,0317 & 0 & 0 \\
\hline \hline
\end{tabular}

Figure 8(a) represent root location of characteristic equation of control system after compensated with $K_{p} 1.5$, it gave information of value -12.32 at real axis and -888.7 \pm $1.472 \times 10^{4} \mathrm{j} \omega$, those number still at negative value, so according to Root Locus method, the system still stable. Figure 8(b) inform us the Nyquist diagram of the system, it is still not encircle the $(-1,+\mathrm{j} 0)$ point, so according to Nyquist criteria, the system are stable.

Design results were the basic requirements for control system assembling process into prototype, Figure 10 shows PLC programming for $K_{p} 1.5$, note that the difference between input and output shown on rung 2, were multiplied by 3 and divided by 2 on the next two rung.

After assembled into rotary flexible fixture, control system then being tested for its performance in angular positioning, by measuring output voltage of angular sensor attached to rotary angular positioning component and compare it to ideal value. Figure 11 are the graphical representation of angular positioning component's \%error at selected angles, this value were governed by equation (5).

$$
\% \text { error }=\left[\frac{(\text { ideal value }- \text { measured value })}{\text { ideal value }}\right] \times 100 \%
$$
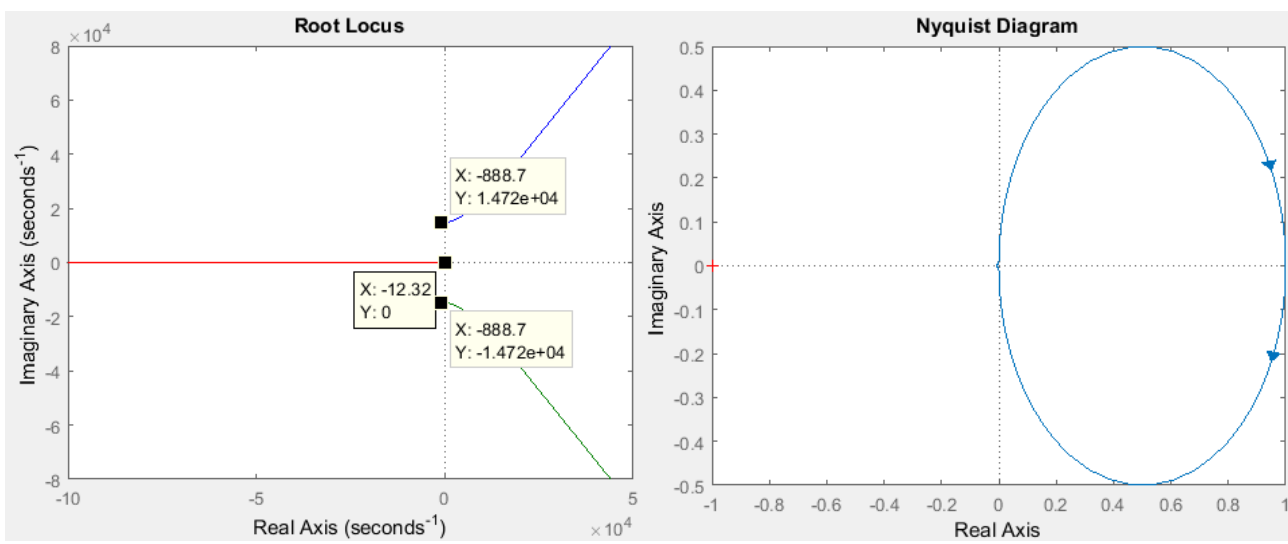

Figure 8. (a) Root locus representation of the system with $K_{p}$ 1.5; (b) Nyquist diagram of the system with $K_{p} 1.5$.

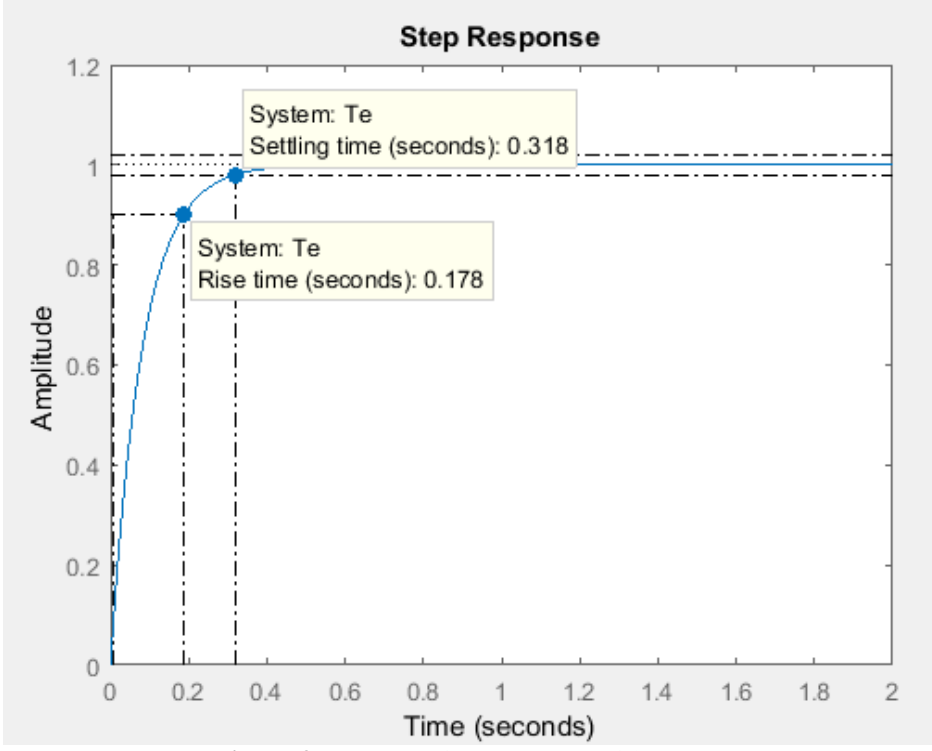

Figure 9. System's time response with $\mathrm{K}_{\mathrm{p}} 1.5$. 


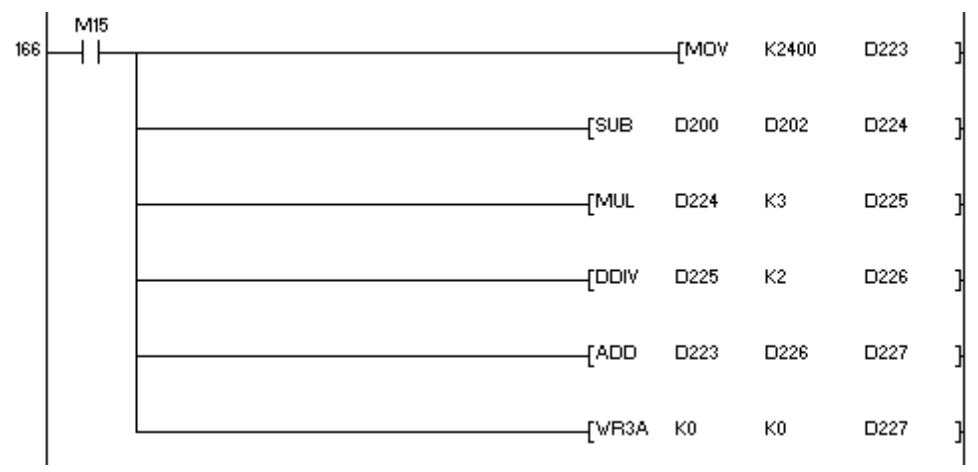

Figure 10. PLC programming with $\mathrm{K}_{\mathrm{p}} 1.5$.

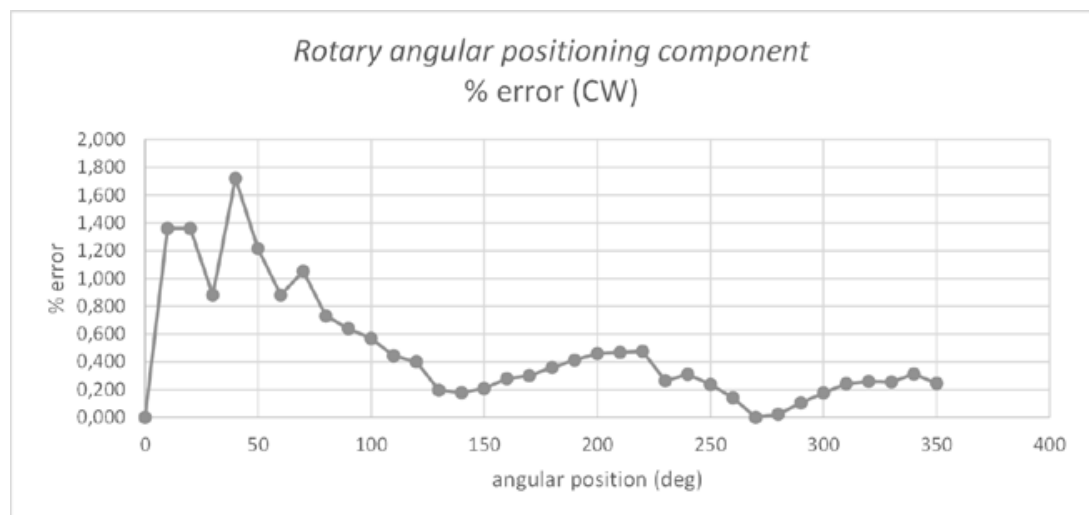

Figure 11. PLC angular positioning component’s \%error at selected angles.

\section{CONCLUSION}

The result from stability analysis, shows there were no sign change on first column of Routh table, all its roots located at LHP with exact locations at axis -12.32, and $888.7 \pm 1,472 \times 10^{4} \mathrm{j} \omega$, and Nyquist diagram shows that no encirclement of point $(-1+\mathrm{j} 0)$, the system stable according to Routh-Hurwitz, Root locus and Nyquist criteria. System's rise time rise time 0.267 seconds and settling time 0.476 seconds, not satisfy design target of rise time 0.2 seconds and settling time 0.4 seconds. Proportional gain $\mathrm{K}_{\mathrm{p}}$, one part of PID compensator, then added to the system, after manual tuning the system reach rise time 0.178 and settling time 0.317 second at $K_{p} 1.5, K_{i} 0$ and $K_{d} 0$, the design target were satisfied. The system yield zero steady state error throughout design process with allowable error $\pm 2 \%$.

As can be seen at Fig 7, the control system's time response were mimic those of overdamped system's behaviour [9]. This is the result of the use of worm and worm-gear pair that was known for its poor efficiency[10], resulting in quite large energy dissipation because of friction between worm and worm-gear. To reduce energy dissipation, it is recommended to use smaller pitch of worm, lower lead angle and pressure angle of worm-gear. The selection of material also important, and more importantly to use a proper lubrication.

\section{REFERENCES}

[1] E. G. Hoffman, Jig and fixture design, 5th ed. Australia: Thomson/Delmar Learning, 2004.

[2] W. Bolton, Programmable logic controllers, 5th ed. Burlington Mass: Newnes, 2009.

[3] F. D. Petruzella, Programmable logic controllers, 4. ed. New York : McGraw-Hill, 2011.

[4] N. S. Nise, Control systems engineering, 6. ed. Hoboken, New Jersey: Wiley, 2011.

[5] W. Bolton, Instrumentation and control systems. Oxford: Elsevier/Newnes, 2004.

[6] H. D. Laksono, M. Mazues, and W. Diafridho, "Analisa kestabilan sistem kendali eksitasi generator Tipe Arus Searah Tanpa dan dengan Pengendali berdasarkan pendekatan tanggapan frekuensi,” J. Nas. Tek. ELEKTRO, vol. 5, no. 3, pp. 350-359, Oct. 2016.

[7] R. C. Dorf and R. H. Bishop, Modern control systems. Boston, Massachusetts: Pearson, 2011.

[8] J. R. Hackworth and F. D. Hackworth, Programmable logic controllers: programming methods and applications. Harlow: Prentice Hall, 2004.

[9] S. S. Rao, Mechanical vibrations, 5th ed. Upper Saddle River, New Jersey: Prentice Hall, 2011.

[10] R. G. Budynas and J. K. Nisbett, Shigley's mechanical engineering design, 9. ed. New York: McGraw-Hill, 2011. 